\title{
Anaesthesia
}

\section{Time to stop sniffing the air: snapshot survey}

Chris Johnson, Neville W Goodman

\section{Introduction}

Generations of anaesthetists have been taught Ivan Magill's descriptions "sniffing the morning air" and "draining a pint of beer" to help them to position a patient's head for tracheal intubation. ${ }^{1}$ A more explicit description is that the neck is flexed forward to about $35^{\circ}$ using one pillow under the head, which is extended on the neck so that the face is tilted back $15^{\circ}$ from the horizontal. " "Sniffing" is commonly used in teaching material $^{2}$ but features less commonly in research papers; Lim et al mention the sniffing position, although they cite no reference nor describe the position. ${ }^{3}$

Cattermole "wondered whether those being taught intubation ever had sniffed the morning air [themselves]." $\mathrm{He}$ asked 40 non-medical undergraduates and graduates aged 18-29 to adopt one of the two positions referred to by Magill. From his findings, he concluded that the "drinking" illustration would be better for teaching, because it was a more accurate description and more relevant to young people, but "sniffing" is the term more widely used in teaching.

We wondered whether anaesthetists, who are skilled at intubation, would demonstrate the position well. We wondered whether Magill's description was, in fact, useful at all.

\section{Participants and methods}

We asked all anaesthetists attending a departmental audit meeting, singly and unseen, whether they had heard the phrase "sniffing the morning air." We then asked them to stand upright, side on to a camera, and to adopt the position. We took a single digital photograph (Canon PowerShot S70) and three measurements (Screen Protractor v3.2, Iconico Inc): the angle of the neck with the vertical, the line of sight with the horizontal, and the hip to shoulder line with the vertical (figure).

\section{Results}

All 21 anaesthetists (14 career grades and 7 trainees) were familiar with the phrase "sniffing the morning air." The median angle of the neck from the vertical was $25^{\circ}$ (interquartile range $16.5^{\circ}-28.5^{\circ}$; full range $14^{\circ}-41^{\circ}$ ); the median angle of line of sight from the horizontal was $19^{\circ}\left(14^{\circ}-25^{\circ} ; 7^{\circ}-37^{\circ}\right)$. Fifteen anaesthetists stood more or less upright, with a hip to shoulder angle of

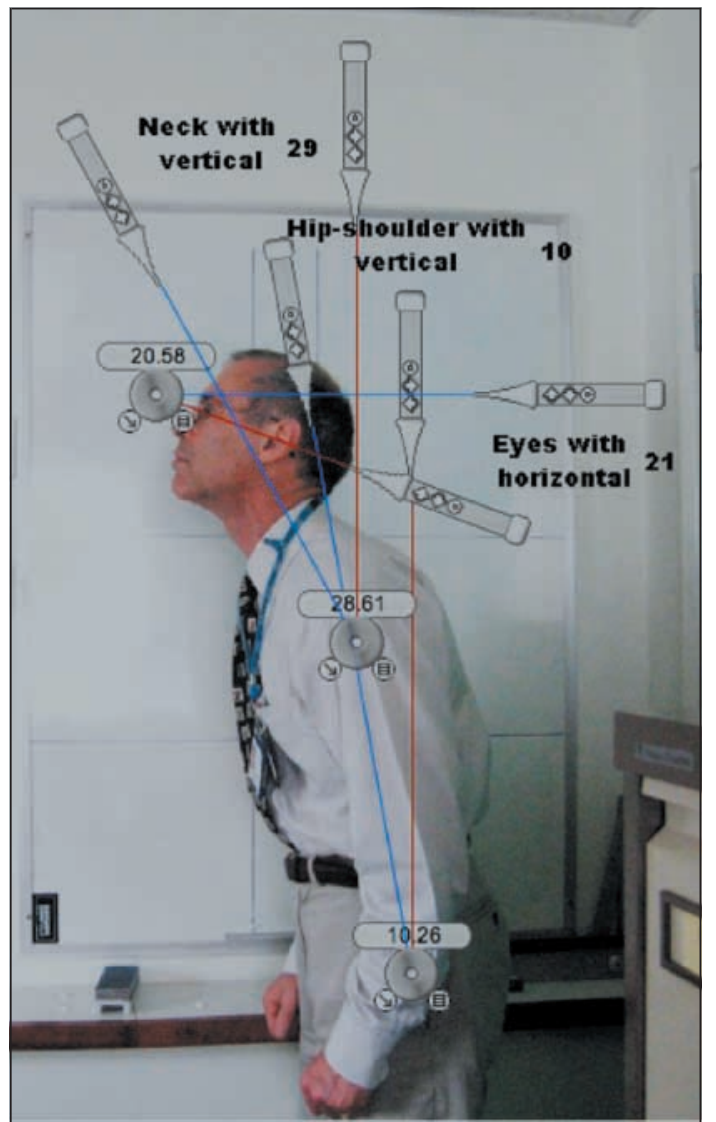

Southmead

Hospital, Bristol BS10 5NB

Chris Johnson consultant

anaesthetist

Neville W

Goodman

consultant

anaesthetist

Correspondence to:

N W Goodman

nev.w.goodman@

bris.ac.uk

BMJ 2006;333:1295-6 
comfortable but better positioned for controlling the airway.

Anaesthesia owes a great debt to Magill, but there seems little point in continuing to use his description of the best patient position when even those familiar with airway control demonstrate it so variably. It is better to advise putting a pillow under the head to flex the neck, and then extending the head on the neck.

Contributors: The project was CJ's idea. NWG took the photos and measured the angles. Both wrote the paper and will act as guarantors. Neither has anything against Sir Ivan Magill, who was more skilled at intubation than they will ever be.

Funding: No funding was sought.

Competing interests: None declared.
Ethical approval was not sought; the photographs were taken at a departmental clinical governance meeting after discussion about teaching intubation. There was no judgment of performance or assessment of any of the anaesthetists, all members of the department who attended that meeting.

1 Pinnock C, Lin T, Smith T, eds. Fundamentals of anaesthesia. London: Greenwich Medical, 1999:49.

2 Goldsack N, Howell D, Marshall R, Montgomery H. Emergency! Student BMJ 1999;7(2). www.studentbmj.com/back_issues/0299/data/0299ed1. $\mathrm{htm}$

3 Lim SL, Tay DHB, Thomas E. A comparison of three types of tracheal tube for use in laryngeal mask assisted blind orotracheal intubation. Anaesthesia 1994;49:255-7.

4 Cattermole GN. Sniff the morning air or drink a pint of beer? Anaesthesia 2002;57:411.

(Accepted 11 October 2006)

doi $10.1136 /$ bmj.39015.726690.47

\section{A village medical mystery}

In the autumn of 1846, Boston dentist William Morton showed that ether could be used effectively as an anaesthetic. A few months later, an American paddle steamer, the Acadia, docked in Liverpool. In its cargo were precious gift packs of this newly discovered anaesthetic bound for three hospitals-University Hospital, London; Edinburgh Infirmary; and Penrhyn Quarry Hospital, Bethesda, north Wales.

Why had our little quarry hospital been so honoured? After consulting archives and old newspapers, I have come to the following conclusion.

I believe that the ether packs were addressed not to specific hospitals but to expert surgeons who worked in them-the famous Dr Liston at University Hospital, the famous Dr Simpson at the Edinburgh Infirmary, and the not quite so famous but equally dexterous Dr Hamilton Roberts at Penrhyn Quarry Hospital. These three men shared a common gift: they were reputed to be able to perform a thigh amputation in 60 seconds flat. Indeed, it was said that Dr Simpson could do it in 48 seconds.

So the first operations on etherised patients in Britain were carried out in London, Edinburgh, and Bethesda, north Wales. In May 1847, the North Wales Chronicle reported: "An injured Welsh quarry man had his leg amputated within the sounds of the River Ogwen. Surgeon Hamilton Roberts in the presence of three local general practitioners, Drs. Pring, Richards and Churchill performed the operation. The revived patient's declaration that he had suffered no pain resounded through an astonished North Wales." On this day the gruesome looking operating table was mercifully declared obsolete.

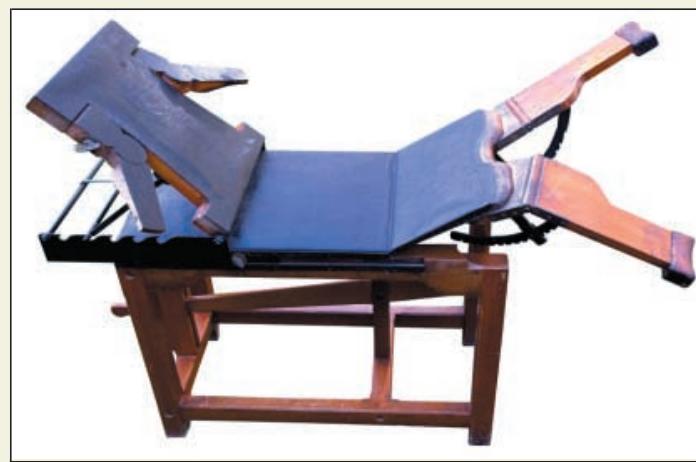

Fig 1 Operating table from the Penrhyn Slate Quarry Hospital. Now residing in the Exhibition Room, Penrhyn Castle

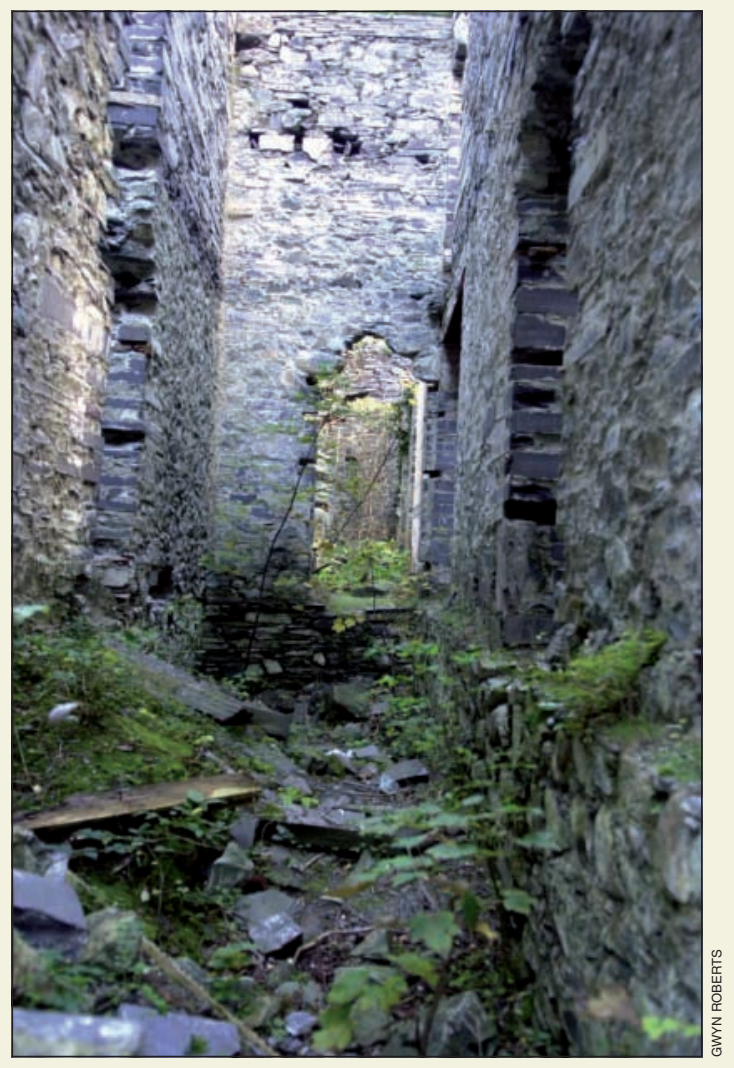

Fig 2 Ruins of Penrhyn Quarry Hospital. The quarry once employed 2000 men and had its own hospital and doctor on site. Operations requiring amputations were common

But this solves only half the mystery. How had the Bostonians who dispatched the ether heard of surgeon Hamilton Roberts in faraway Wales? Perhaps it was via the hundreds of north Wales quarrymen who emigrated to Boston in the $1840 \mathrm{~s}$.

J Aelwyn Roberts vicar, Haulfre Vicarage, Llandegai, Bangor (aelwynroberts@tiscali.co.uk) 